\title{
PENGARUH VARIASI SUSUNAN SERAT ECENG GONDOK (EICHHORNIA CRASSIPES) DENGAN RESIN POLYESTER SEBAGAI BAHAN KOMPOSIT ALTERNATIF ROMPI ANTI PELURU
}

\author{
Bahar Qulub Iqbal Hanifi", H. Purwanto., Imam Syafa'at \\ Jurusan Teknik Mesin, Fakultas Teknik, Universitas Wahid Hasyim \\ Jl. Menoreh Tengah X/22, Sampangan, Semarang 50236. \\ "Email: baharqulubiqbal@gmail.com
}

\begin{abstract}
Abstrak
Serat eceng gondok merupakan salah satu material natural fiber alternatif dalam pembuatan komposit. Batang dari tanaman eceng gondok jika diproses dapat menghasilkan serat. Rompi anti peluru yang digunakan oleh militer, kepolisian, maupun sipil pada umumnya terbuat dari bahan serat aromatik polymides atau aramid. Serat-serat tersebut sampai saat ini diperoleh dengan cara impor dengan harga yang sangat mahal. Rompi anti peluru berbahan komposit serat telah banyak dikembangkan dari bahan lokal. Tulisan ini mengkaji sifat fisis dan mekanis serta kemampuan balistik komposit polimer polyester variasi susunan serat eceng gondok (eichhornia crassipes) sebagai bahan alternatif alami rompi anti peluru. Panel komposit dibuat dengan susunan serat searah vertical dan susunan serat berlapis (vertical/horizontal) dengan perbandingan vraksi volume serat dan matrik $30 \%$ dan $70 \%$ dengan ketebalam $10 \mathrm{~mm}$. Hasil pengamatan pada serat eceng gondok menunjukan struktur mikro cenderung berbentuk silinder sehingga mempunyai penampang berbentuk lingkaran dan serat berwarna kuning kecoklatan. Nilai uji tarik rata-rata serat eceng gondok adalah 7,696 Kg/mm${ }^{2}$. Kekuatan tarik komposit dengan susunan serat berlapis (vertical/horizontal) lebih tinggi dengan yield stress 9,522 MPa dan max stress 10,408 MPa dibandingkan dengan susunan serat searah vertical yaitu yield stress 4,535 MPa dan max stress 10,111 MPa. Hasil pengujian balistik menunjukan komposit dengan susunan berlapis juga lebih mampu menyerap energi impak dari proyektil.
\end{abstract}

Kata kunci: polyester, serat eceng gondok, susunan serat, rompi anti peluru.

\section{PENDAHULUAN}

Komposit memiliki keunggulan tersendiri apabila dibandingkan dengan bahan alternatif lain seperti lebih kuat, ringan, ekonomis dan ramah lingkungan (Widodo, 2008). Komposit berpenguat serat alam dari eceng gondok, perlu dilakukan pencampuran dengan resin. Resin sebagai matriks yang digunakan adalah tipe resin polyester dimana resin polyester mempunyai harga yang murah dan mudah digunakan. Selain itu polyester mempunyai daya tahan terhadap impak, tahan terhadap segala cuaca, transparan dan efek permukaan yang baik. Kerugian dari penggunaan resin polyester adalah daya rekat yang kurang baik dan sifat inhibisi dari udara dan filler (Nindhia, 2011).

Prosentase dan susunan serat pada matrik komposit dapat berpengaruh pada kekuatan komposit. Prosentasi 30\% serat eceng gondok dan $70 \%$ resin polyester mempunyai kekuatan yang paling optimal (Slamet, dkk 2012). Bentuk serat pendek, serat panjang, serat dengan susunan tertentu juga berpengaruh terhadap daya ikat antara serat dan polyester. Sehingga variasi susunan serat juga dapat mempengaruhi kekuatan komposit (Asrul 2014).

Pada penelitian pembuatan bahan rompi anti peluru menggunakan bahan dasar serat polyester (Zubaidi, 2008), hasil uji menunjukkan bahwa panel dari serat polyester dapat mencapai level II pada standar internasional NIJ. Dibanding panel dari komposit serat rami, panel dari serat polyester mempunyai kelebihan dalam hal kelenturan, kestabilan, dan lebih nyaman dalam pemakaiannya.

Tujuan dari tulisan ini adalah untuk mengetahui dan menganalisa struktur kekuatan tarik serat eceng gondok, kekuatan tarik variasi susunan serat eceng gondok serta ketahanan balistik variasi susunan serat eceng gondok pada matrik polyester

\section{METODE PENELITIAN}

Bahan utama yang digunakan dalam penelitian ini meliputi serat eceng gondok (eichhornia crassipes), resin yang digunakan adalah polyester yukalac 157® BTQN-EX, harder metyl keton peroksida (MEKPO). Alat yang digunakan dalam penelitian meliputi 
cetakan spesimen, gelas ukur, stand spesimen, alat uji tarik, chronograph, senapan angin, peluru, sikat kawat, cutter, margarin, gunting, lilin malam, penggaris dan gunting.

Penelitian dilakukan di kampus Universitas Wahid Hasyim Semarang. Adapun beberapa prosedur pengujian dalam penelitian ini yaitu persiapan bahan penelitian dan pembuatan spesimen. Pengujian yang dilakukan meliputi uji tarik serat tunggal, uji tarik komposit, uji balistik dan uji makro.

Tanaman eceng gondok yang digunakan adalah yang sudah berumur \pm 8 bulan. Eceng gondok dijemur lalu diambil seratnya. Potong serat eceng gondok dengan ukuran $150 \mathrm{~mm}$. Proses pembuatan komposit serat eceng gondok dengan menggunakan matrik polyester dan katalis serta cetakan spesimen dengan ukuran 15 x $15 \mathrm{~cm}$ ketebalan spesimen $10 \mathrm{~mm}$. Untuk cetakan uji tarik menggunakan cetakan sesuai standar ASTM D 638 . Fraksi volume 30\% serat dan $70 \%$ polyester. Katalis yang digunakan adalah MEKPO dengan prosentase $1 \%$ dari resin polyester yang digunakan. Proses pengujian balistik menggunakan senapan angin hentak dan peluru jenis domade kaliber 4,5 mm dengan jarak tembak $5 \mathrm{~m}$. Skema pengujian balistik seperti terlihat pada Gambar 1.

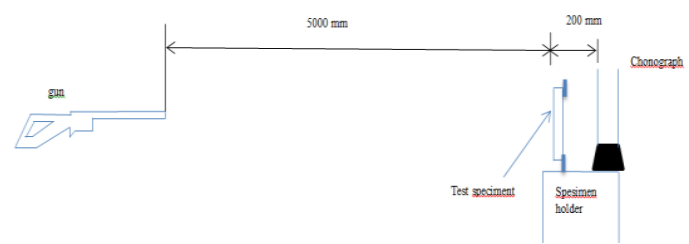

Gambar 1. Skema pengujian balistik

\section{HASIL DAN PEMBAHASAN}

Hasil uji tarik serat di ketahui nilai kekuatan tarik rata-rata serat eceng gondok adalah $7,696 \mathrm{Kg} / \mathrm{mm}^{2}$. Kekuatan tarik serat eceng gondok lebih kecil dibandingkan serat kulit pohon randu yang memiliki kekuatan tarik 149,914 MPa (Sugirinoto, 2016).

Hasil pengujian tarik komposit dengan variasi susunan searah vertical dan susunan berlapis (vertical/horizontal) seperti terlihat pada Gambar 2.

Susunan serat berlapis (vertical) horizontal) menghasilkan yield stress yang lebih baik dibandingkan dengan susunan searah vertical. Hal ini disebabkan oleh variasi susunan seratnya, semakin banyak variasi susunan serat maka akan semakin tinggi kekuatan tariknya. Akibat tegangan yang bekerja maka matriks dan serat akan terlepas dari ikatannya tetapi ada sebagian serat masih berikatan sehingga serat tersebut belum dapat tercabut.

Yield stress pada susunan searah vertical rendah karena terjadi pemutusan secara bersamaan antara matrik dan serat yang disebabkan gaya tarik searah dengan susunan serat eceng gondok.

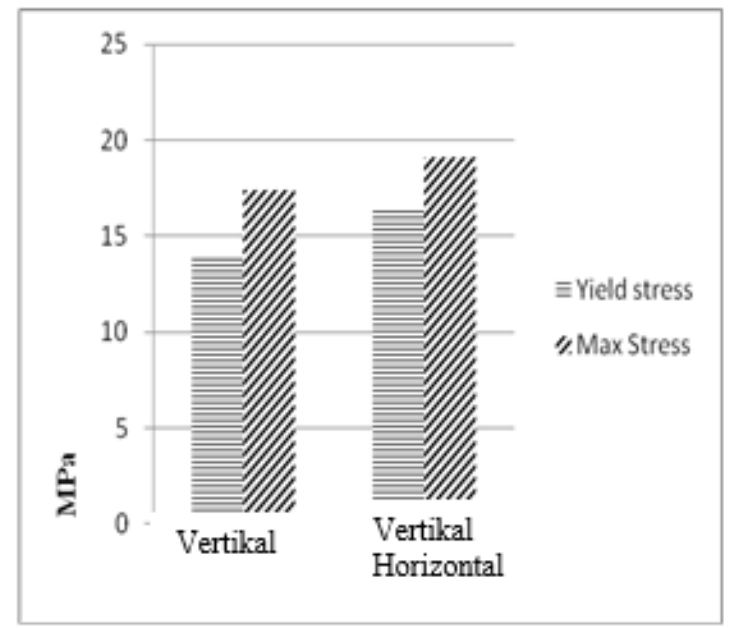

Gambar 2. Grafik yield stress dan max stress uji tarik komposit serat

Gambar 2. menunjukkan hasil uji tarik komposit serat eceng gondok. Dari hasil uji tarik diperoleh nilai yield stress yang paling baik yaitu pada variasi susunan serat berlapis (vertical/horizontal) dengan nilai sebesar 17,423 dan nilai max stress sebesar 19,077 MPa. Hal ini dipengaruhi oleh variasi susunan serat, semakin banyak variasi susunan serat maka akan semakin tinggi kekuatan tariknya. Akibat tegangan yang bekerja maka matriks dan serat akan terlepas dari ikatannya tetapi ada sebagian serat masih berikatan sehingga serat tersebut belum dapat tercabut.

Berdasarkan pengamatan dengan menggunakan miksroskop makro pada penampang patahan komposit spesimen uji tarik, variasi susunan serat berlapis (vertical/horizontal) mengalami proses viber pull out dan pada variasi susunan serat searah vertical antara serat dan matrik cenderung lebih terikat kuat. Seperti terlihat pada Gambar 3. Pada variasi susunan serat searah (vertical/horizontal) kondisi spesimen setelah dilakukan uji tarik mengalami patah dan serat tercabut dari matriknya. Hal tersebut dipengaruhi oleh proses viber pull out pada 
saat proses uji tarik. Gambar 3. Menunjukkan variasi susunan serat searah vertical, kondisi serat cenderung putus hampir bersamaan dengan resinnya. Hal ini disebabkan oleh karena gaya luar yang diberikan berupa gaya tarik yang searah dengan susunan serat eceng gondok Asrul (2014).

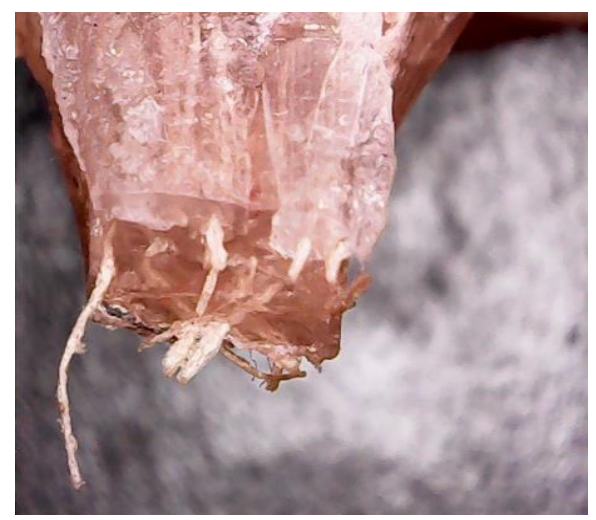

Gambar (a) variasi susunan berlapis (vertical/horizontal)

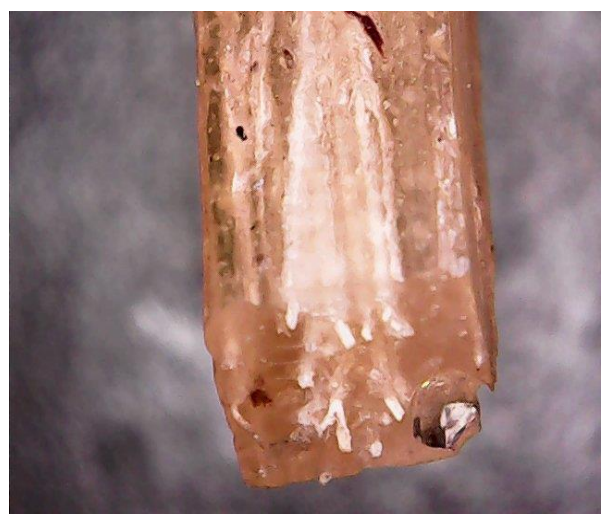

(b) variasi susunan vertical.

Gambar 3. Foto makro spesimen uji tarik komposit serat searah dan berlapis

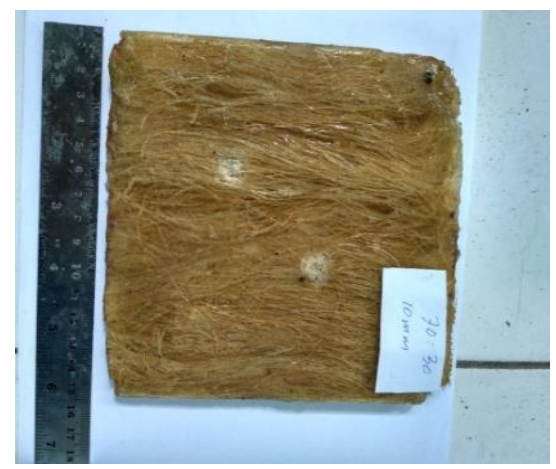

(a) susunan serat searah vertical
Pengujian balistik pada masing-masing variasi susunan serat memperlihatkan kedua panel komposit mampu menahan laju proyektil seperti yang terlihat pada Gambar 4.

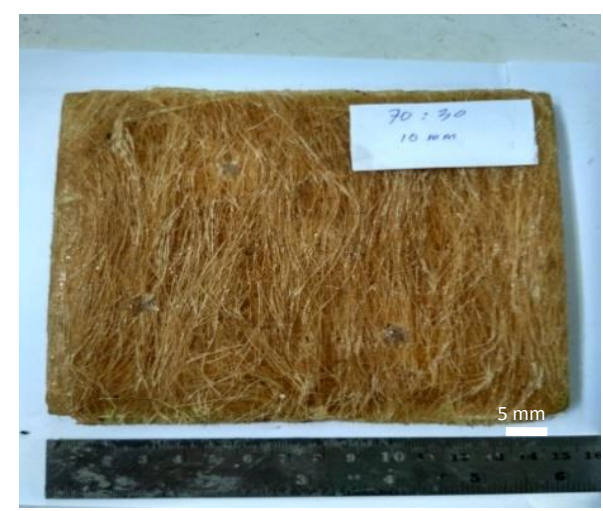

(b) susunan serat berlapis (vertical/horizontal)

Gambar 4. Spesimen hasil uji balistik

Tabel 1. Hasil pengukuran kecepatan sisa pengujian balistik

\begin{tabular}{llll}
\hline $\begin{array}{c}\text { Susunan } \\
\text { serat }\end{array}$ & $\begin{array}{c}\text { Kecepata } \\
\text { n peluru } \\
\text { rata-rata } \\
(\mathbf{m} / \mathbf{s})\end{array}$ & $\begin{array}{c}\text { Kondisi } \\
\text { Panel }\end{array}$ & $\begin{array}{c}\text { Sisa } \\
\text { Kecepatan } \\
\text { Hasil } \\
\text { Tembakan } \\
(\mathbf{m} / \mathbf{s})\end{array}$ \\
\hline $\begin{array}{l}\text { Susunan } \\
\text { Searah } \\
\text { vertical }\end{array}$ & 229,81 & $\begin{array}{l}\text { Tidak } \\
\text { tembus }\end{array}$ & 10,85 \\
& & $\begin{array}{l}\text { Tidak } \\
\text { tembus } \\
\text { Tidak }\end{array}$ & 10,48 \\
& & 10,25 \\
tembus & \\
Susunan & & $\begin{array}{l}\text { Tidak } \\
\text { tembus }\end{array}$ & 9,90 \\
berlapis & & Tidak & 9,50 \\
vertical/ & 229,81 & tembus \\
horizontal & & Tidak & 9,40 \\
& & tembus \\
\hline
\end{tabular}

Pengukuran sisa pecahan panel seperti terlihat pada Tabel 1. Rata rata kecepatan sisa pecahan susunan serat berlapis (vertical/horizontal) lebih rendah dibandingkan dengan susunan serat searah vertical. Hal ini disebabkan oleh variasi susunan serat pada susunan berlapis (vertical/horizontal) dapat meredam sisa kecepatan peluru.

Berdasarkan pengamatan secara mikroskopik pada spesimen komposit hasil uji balistik, spesimen dengan nilai sisa balistik terendah terjadi pada variasi susunan serat berlapis (vertical/horizontal) dengan nilai sisa balistik sebesar $9.40 \mathrm{~m} / \mathrm{s}, 9.50 \mathrm{~m} / \mathrm{s}$ dan 9.90 
$\mathrm{m} / \mathrm{s}$. Serat terikat kuat dengan resin pembentuknya dan sisa proyektil tertahan pada penampang spesimen, sehingga dapat meredam sisi kecepatan dan efek peluru agar badan tidak terlalu sakit saat peluru menghantam panel komposit.

\section{KESIMPULAN}

Dari hasil penelitian dan analisa data maka dapat disimpulkan :

1. Struktur mikro permukaan serat eceng gondok cenderung berbentuk silinder sehingga mempunyai penampang berbentuk lingkaran dan serat berwarna kuning kecoklatan. Nilai uji tarik serat eceng gondok adalah $9,56 \mathrm{Kg} / \mathrm{mm}^{2}$.

2. Nilai uji tarik terbaik yaitu pada komposit variasi susunan serat berlapis (vertical/horizontal) dengan yield stress 17,423 MPa dan max stress 19,077 MPa. Hal ini menunjukkan bahwa semakin banyak variasi susunan serat maka akan semakin kuat.

3. Nilai ketangguhan balistik susunan serat berlapis (vertical/horizontal) adalah 9.6 $\mathrm{m} / \mathrm{s}$. Nilai ini berbanding terbalik dengan hasil uji tarik komposit. Dimana semakin rendah nilai ketangguhan balistik, maka kekuatan kompositnya akan semakin baik. Pada susunan serat belapis lebih bisa meredam kecepan peluru dibandingkan dengan susunan serat searah vertical. Hal ini disebabkan karena terjadi bonding dimana susunan serat berlapis (vertical/horizontal) terikat kuat dengan resinnya sehingga sisa proyektil masih menempel pada permukaan spesimen uji balistik.

\section{SARAN} adalah:

Saran dari penelitian yang telah dilakukan

1. Pada saat penyusunan serat berlapis (vertical/horizontal), usahakan serat tersusun secara rapi dan merata, hal ini bertujuan agar mengurangi proses fiber pull out demi memperoleh hasil komposit yang maksimal.

2. Pembuatan cetakan spesimen uji tarik alangkah baiknya menggunakan bahan $\mathrm{kaca} / \mathrm{kayu}$ agar cetakan cepat mengering dan mempermudah pada saat pengambilan.

\section{DAFTAR PUSTAKA}

Hendri Hestiawan dan Asrul Fauzi, 2014.” Studi Pengaruh Fraksi Volume dan Susunan Serat Terhadap Kekuatan Tarik dan Bending Komposit Resin Berpenguat Serat Rotan (Calamus Trachycoleus)". Teknik Mesin Universitas Bengkulu. Bengkulu.

Opa Slamet S, Burnawi, kaidir., 2008. "Analisa sifat mekanik material komposit dari polyester resin berpenguat serat sabut kelapa yang diberi perlakuan alkali ( $\mathrm{NaOH} 25 \%$ ) ',. Teknik Mesin Universitas Bung Hatta. Padang.

Sugirinoto, S.M Bondan Respati, Helmy Purwanto., 2016 "Analisa Kekuatan Tarik Dan Mikrostruktur Serat Kulit Pohon Randu (Ceiba Pentandra L)Yang Direbus Dengan Air Kunyit (Curcuma Longa)', Teknik Mesin Universitas Wahid Hasyim. Semarang.

Tjokorda Gede Tirta Nindhia, Daud Simon Anakottapary, 2011. 'Baju Tahan Peluru Ekonomis Terbuat Dari Komposit Polimer Diperkuat Butiran Silikon Karbida Dan Serat Karbon', Teknik Mesin Universitas Udayana. Bali.

Widodo dan Basuki,. 2008. "Analisa Sifat Mekanik Komposit Epoksi Dengan Penguat Serat Pohon Aren (ijuk) Model Lamina Berorientasi Sudut Acak" . Jurnal Teknologi Technoscienta. Malang. Indonesia : ITN Malang.

Zubaidi, Moekarto M, Santoso S., 2008. 'Pembuatan Rompi Anti Peluru Menggunakan Bahan Dasar Serat Poliester'. Balai Besar Tekstil. Bandung. 